\title{
Impact of controlling zero sequence current in a three- phase four-wire LV network with PV units
}

\author{
Fida Hasan Md Rafi, Student member, IEEE, M. J. Hossain, Senior Member, IEEE, Md. Shamiur Rahman, Student \\ member, IEEE, J. Lu, Senior Member, IEEE \\ Queensland Micro and Nano Technology Center, Griffith School of Engineering, \\ Griffith University, Gold coast, Australia. \\ Fida.rafi@griffithuni.edu.au, j.hossain@griffith.edu.au, mdshamiur.rahman@griffithuni.edu.au, j.lu@griffith.edu.au
}

\begin{abstract}
The dynamic impacts of controlling zero sequence current in a three-phase four-wire low voltage (LV) distribution network with a four-leg voltage source inverter (VSI) and PV installations are investigated in this paper. The PV VSI is designed to control active power at unity power factor (p.f) with additional neutral and zero sequence current controls. Inherently, most of the three-phase four-wire $L V$ distribution networks exhibit voltage unbalance characteristics due to the connection of single- and three-phase nonlinear loads as well as occurrence of asymmetrical faults in the networks. The control over zero sequence current can improve the inherent voltage unbalance in the $L V$ networks. The transient characteristics of the unbalanced network are investigated utilizing a widely used software environment, PSCAD/EMTDC, for the Energex 11 kV/420 V distribution network in Brisbane, Australia. The performance of the designed four-leg VSI is compared with the traditional three-leg VSI experiencing different asymmetrical faults. The results show that, with the additional degree of freedom from the four-leg VSI, faster fault recovery and lower MVA requirement can be achieved for unbalanced LV networks.
\end{abstract}

Index Terms-Voltage unbalance, four-leg inverter, neutral current, zero sequence component, three-phase four-wire LV network.

\section{INTRODUCTION}

Due to the rapid integration of hybrid renewable energy sources, such as photovoltaic units, battery energy storage systems, and wind turbines into the traditional passive distribution networks, the current power industries are facing great challenges. Among several challenges associated with renewable energy integrations, especially in LV distribution networks, the control over neutral and zero sequence currents are getting much attention in recent years. This is due to the common incident of unbalanced loading in the LV networks caused by several single-phase load connections [1] [2]. Generally, neutral wire connection is provided for housing both three- and single-phase loads in LV distribution networks, making it a three-phase four-wire connection.

In the absence of neutral wire connection, traditional threeleg inverters are utilized considering balanced LV networks.
Perfectly grounded neutral system is considered in case of a balanced network which has zero neutral voltage, whereas in real scenarios, the neutral grounding resistance can cause higher neutral current resulting in higher thermal stress and increasing losses in the connected systems [3]. With the sensitive electronic equipment, excessive neutral current can cause operation failure of the equipment [4]. Utilization of a spilt dc-link capacitor is a well-recognized approach for three-leg inverter with four-wire connections; however, it produces distorted symmetrical voltage outputs even with larger dc-capacitors [5]. Several significant research works have been carried out for the four-leg inverters, where the additional two switches in the fourth-leg are utilized to control the neutral current, and correspondingly the zero sequence current produced from the unbalanced distribution systems [6-8].

For a balanced system, the active and reactive powers of the distributed generators are generally controlled by adjusting the voltage and current in a synchronously rotating frame $(a b c-d q 0)$ [9, 10]. In case of unbalanced systems, initially the voltage and current phasors need to be transformed to symmetrical components, i.e. positive, negative, and zero sequence components [11]. For simple proportional and integral (PI) type linear controllers, the symmetrical components are generally transformed in to individual dq0 ( \pm ) components. Different control design techniques are presented in the literature considering voltage unbalance [12], unsymmetrical faults [13], and nonlinear loads utilizing the transformed quantities. However, in those papers primary focus was given to control only the positive and negative sequence components. Authors in [7] proposed an unbalanced controller considering homo-polar sequence components, however, the correlation of zero sequence with the neutral currents is missing.

In this paper, the four-leg PV VSI is designed with the aim of reducing the zero sequence and neutral currents in an unbalanced LV network. A relation has been developed to control both currents with a single reference input which makes the controller more robust during unbalanced scenarios. 


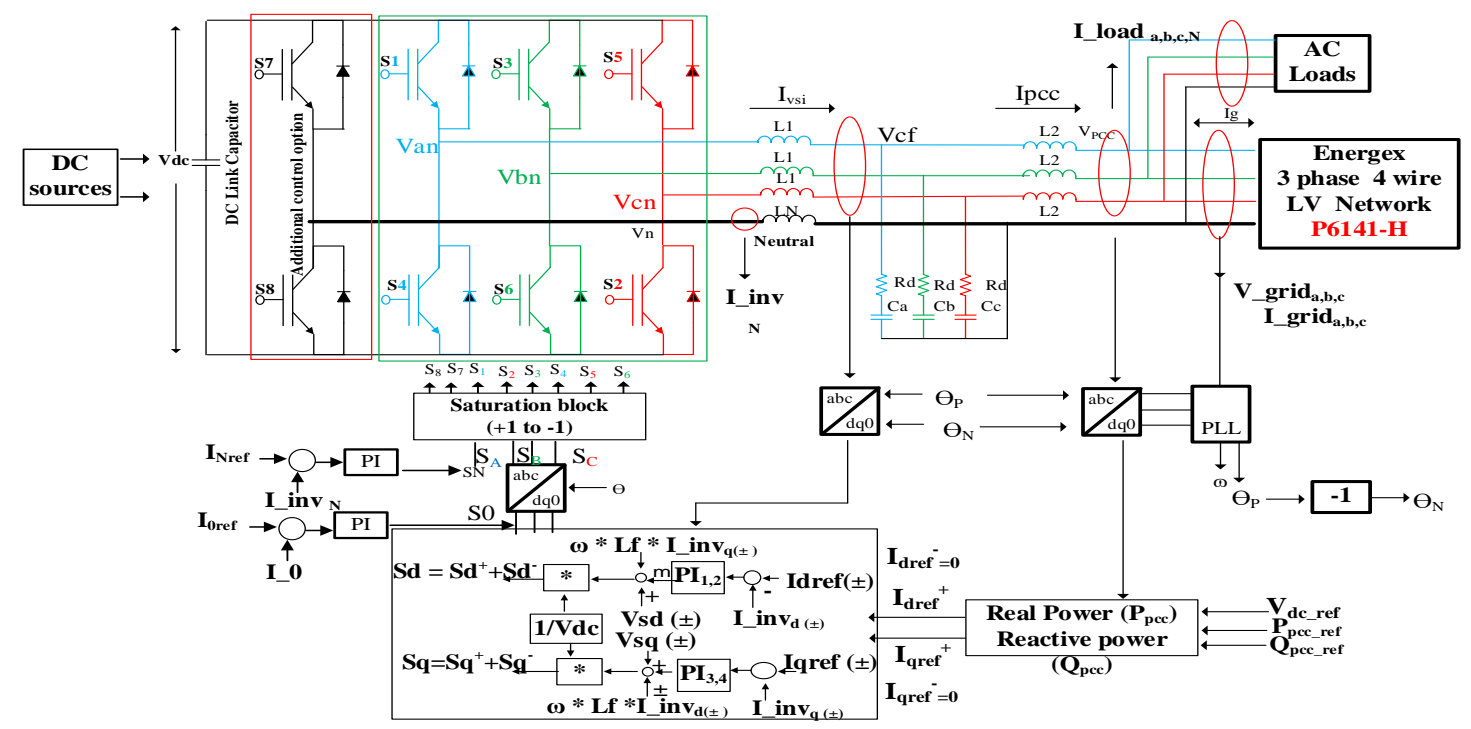

Figure 1. Designed four-leg VSI connection with LV network.

The results obtained from the four-leg VSI are compared with those produced by a traditional three-leg VSI at the same connection point with similar design structures. Different faults have been applied at the point of common coupling (PCC) to evaluate the transient effects in the unbalanced LV system. The results show similar dc-voltage regulation performance from both of the three- and four-leg VSIs. However, the four-leg VSI improves the dc-bus voltage oscillation during asymmetrical faults, for example, double line to ground (2L-G) and single line to ground (1L-G) faults. The significant improvement is observed in less reactive power requirement from the grid, and the magnitude reduction in zero sequence voltage during asymmetrical faults, which performs robust fault recovery and less MVA requirement from the designed four-leg VSI compared to three-leg VSI.

\section{SYSTEM DESCRIPTION}

The designed PV system with three-leg and four-leg VSIs is connected in a three-phase four-wire LV distribution network which is designed utilizing a year real customers' load data from Newmarket zone substation area, Energex in Brisbane, Australia as shown in Fig. 1. The PV system is designed to provide $13 \mathrm{~kW}$ active power at unity power factor. The VSI can also be operated at four-quadrant mode as shown in ref. [14]. Generally, for three-leg VSI, the zero sequence component is considered as zero, whereas for the four-leg VSI the additional fourth leg enables the control over the neutral and correspondingly zero sequence components. The zero sequence and neutral currents can be related as:

$$
\begin{aligned}
& I_{n}=-\left(I_{a}+I_{b}+I_{c}\right) \\
& I_{0}=\frac{\left(I_{a}+I_{b}+I_{c}\right)}{3}=-\frac{I_{n}}{3}
\end{aligned}
$$

where, $I a, I b$ and $I c$ are three-phase currents; $\mathrm{I}_{\mathrm{n}}$ the neutral, and $\mathrm{I}_{0}$ the zero sequence currents. The unbalanced voltage and current components are considered as function (f), and can be decomposed into the symmetrical components as shown in Equ. (2). The symmetrical components can be further transformed to synchronously rotating $d q 0^{ \pm}$frame utilizing the PLL angle for positive sequence and taking negative of the PLL angle for negative sequence components as described in ref. [15].

$$
\begin{aligned}
f a b c & =\left[\begin{array}{l}
f a \\
f b \\
f c
\end{array}\right]=f_{a b c}^{+}+f_{a b c}^{-}+f_{a b c}^{0} \\
& =f^{+}\left[\begin{array}{c}
\cos \left(\omega t+\varphi^{+}\right) \\
\cos \left(\omega t+\varphi^{+}-\frac{2 \pi}{3}\right) \\
\cos \left(\omega t+\varphi^{+}+-\frac{2 \pi}{3}\right)
\end{array}\right]+f^{-}\left[\begin{array}{c}
\cos \left(\omega t+\varphi^{-}\right) \\
\cos \left(\omega t+\varphi^{-}+\frac{2 \pi}{3}\right) \\
\cos \left(\omega t+\varphi^{-}-\frac{2 \pi}{3}\right)
\end{array}\right]+f^{0}\left[\begin{array}{c}
\cos \left(\omega t+\varphi^{0}\right) \\
\cos \left(\omega t+\varphi^{0}\right) \\
\cos \left(\omega t+\varphi^{0}\right)
\end{array}\right]
\end{aligned}
$$

The $a b c-\alpha \beta \gamma-d q 0$ transformation results,

$$
\begin{gathered}
{\left[\begin{array}{l}
\mathrm{X}_{\mathrm{d}}^{ \pm} \\
\mathrm{X}_{\mathrm{q}}^{ \pm} \\
\mathrm{X}_{0}^{ \pm}
\end{array}\right]=\left[\begin{array}{ccc}
\cos \theta & \pm \sin \theta & 0 \\
\mathrm{~m} \sin \theta & \cos \theta & 0 \\
0 & 0 & 1
\end{array}\right]\left[\begin{array}{c}
\mathrm{X}_{\alpha} \\
\mathrm{X}_{\beta} \\
\mathrm{X}_{\gamma}
\end{array}\right]} \\
{\left[\begin{array}{l}
\mathrm{X}_{\alpha} \\
\mathrm{X}_{\beta} \\
\mathrm{X}_{\gamma}
\end{array}\right]=\mathrm{V}^{+}\left[\begin{array}{c}
\cos \left(\omega \mathrm{t}+\varphi^{+}\right) \\
\sin \left(\omega \mathrm{t}+\varphi^{+}\right) \\
0
\end{array}\right]+\mathrm{V}^{-}\left[\begin{array}{c}
\cos \left(-\omega \mathrm{t}+\varphi^{-}\right) \\
\sin \left(-\omega \mathrm{t}+\varphi^{-}\right) \\
0
\end{array}\right]+\mathrm{V}^{0}\left[\begin{array}{c}
0 \\
0 \\
\cos \left(\omega \mathrm{t}+\varphi^{0}\right)
\end{array}\right](5)}
\end{gathered}
$$

The control over fourth-leg switching has been described in ref. [6], and is modified utilizing the relation between the neutral and zero sequence currents presented in Equ. (1). Generally, in unbalanced systems, the positive sequence components control the usable active and reactive powers. The negative sequence components are responsible for creating the double frequency oscillation in the output quantities produced from the VSI [15]. The negative sequence components can be controlled using the similar decoupled current control structure as the positive sequence one with the exception in the decoupling terms, and in the references (i.e. the $\mathrm{Id}^{-}$ref and $\mathrm{Iq}^{-}$ref is set to zero) as shown in Fig. 1. The remaining components of the designed model consist of a LCL filter and a conventional PWM (pulse width modulation) switching mechanism, which is applied similarly as the three-leg VSI [16]. The dc-bus voltage is regulated at $800 \mathrm{~V}$ following the patented information from local 
STATCOM manufacturing company, Elevare. The PI controllers are initially tuned using modulus optimum method and further fine-tuned to get optimum response from the designed controller [17]. As the presence of neutral current causes distortion in the voltage and current outputs generated from the VSI, during normal operation, the neutral and zero sequence currents references are set to zero. However, the designed controller can generate desired neutral and zero sequence currents within the maximum set limit of the VSI. The complete design parameters are given in the Appendix.

\section{RESUlTS AND DISCUSSIONS}

The considered LV network consists of both three- and single-phase customer connections and the distance between each customer is within 10-15 m (Urban area). The nominal value of the $\mathrm{X} / \mathrm{R}$ ratio is assumed as unity for the higher resistive urban network [18]. The LV network (11 kV/ 415 $\mathrm{V}$ ) is designed from the $33 / 11 \mathrm{kV}$ upstream network using the distribution transformer (DT) and transmission poles data from an inner northern residential suburb of Brisbane, which are provided by Energex, one of the largest DNOs in Queensland, Australia. The Newmarket zone $11 \mathrm{kV}$ substation supplies electrical power to around 2,373 customers with 8,495 kVA installed loads. The feeder minimum load is around $70 \mathrm{~A}$, and at mid-day is around 100 A. Maximum summer and winter load currents are $150 \mathrm{~A}$ and 250 A, correspondingly. Individual customer's loading has been considered as maximum $2 \mathrm{kVA}$ and minimum $0.55 \mathrm{kVA}$ with power factor 0.95 lagging. The base loading of the network is around $230 \mathrm{~kW}$ and $60 \mathrm{kVAR}$. The LV network mainly consists of three-phase four-wire overhead distribution lines which are supplied from a $750 \mathrm{kVA}$ DT to 150 customers. One-year loading data of individual customer is fed to the designed PSCAD network via calculating the resistive (R) and inductive (L) load values from active and reactive power consumptions. The PV system connection with the LV network is shown in Fig. 2. The LV network includes two mesh/loop networks and the PV VSI is placed at the farthest point from the DT by monitoring inherent unbalance voltages as shown in Fig. 3. It is estimated that under standard testing condition (STC), the PV module generates around $650 \mathrm{~W}$. The peak voltage and current of a single PV module consisting 108 cells in series and 4 cells in parallel are around $81 \mathrm{~V}$ and $8.125 \mathrm{~A}$. The open circuit PV module voltage is around $900 \mathrm{~V}$ [14]. The single line diagram of the detailed network is shown in Fig. 11 in Appendix.

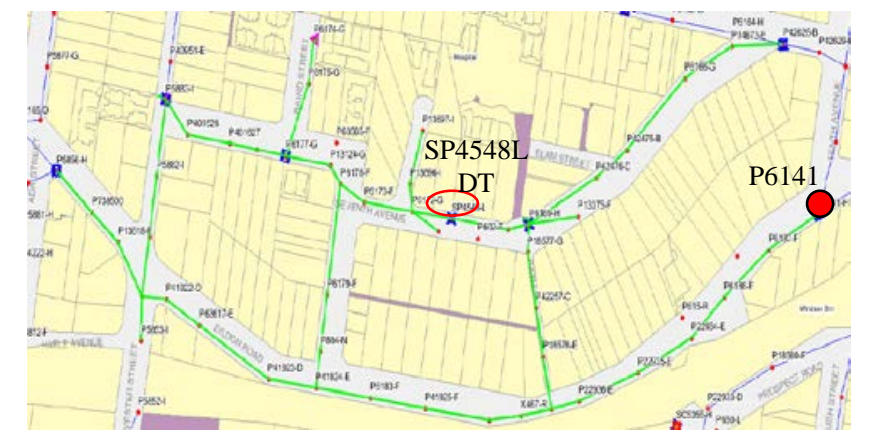

Figure 2. Original LV network transmission poles placement diagram.
The parameters of the installed four-leg VSI at Griffith University's microgrid are used in this paper. Due to the divergent nonlinear loads, the building experiences as high as 80 A neutral current during weekdays as shwon in Fig. 4.

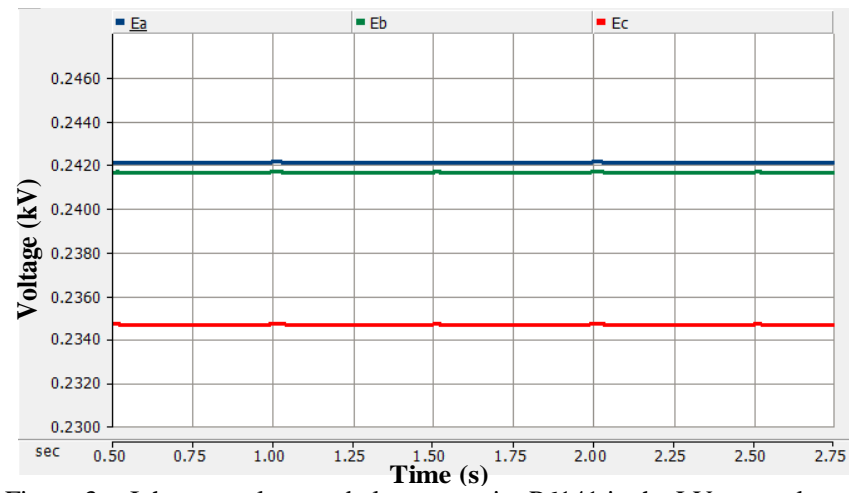

Figure 3. Inherent voltage unbalance at point P6141 in the LV network.

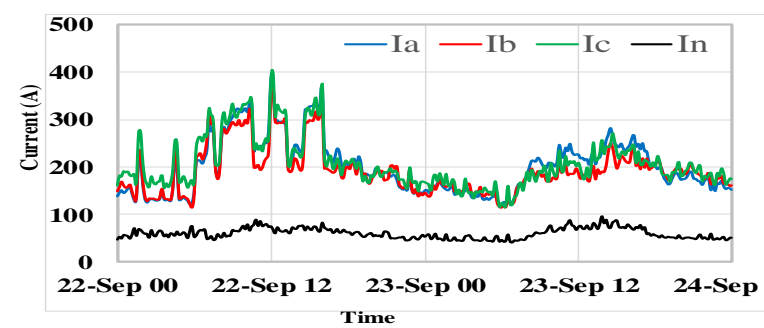

Figure 4. Real currents data of N44 building, Griffith University, Australia.

The purpose of the installed microgrid at Griffith university is to validate the feasibility of the four-quadarnt PV VSI features with aditional neutral current control in Australian LV networks. In our previous paper [14], the significance of having decentralized reactive power control with traditional unity p.f VSI is presented. The aim of this paper is to investigate the significance of controling the zero sequence current; and the results are comapred with those obtained from the traditional three-leg VSI connected with the unbalanced LV network.

\section{A. Neutral current control}

In this case study, the neutral current reference is manually changed to show the independent control over the fourth-leg from the designed four-leg VSI. The maximum neutral and zero sequence currents are calculated based on the MVA limit of the VSI, and is set to maximum $10 \mathrm{~A}$ and 3 A, correspondingly. The reference following operations of the neutral and zero sequence currents are shown in Fig 5. The effects on modulating signals due to reference changing operation of the neutral current controller is shown in Fig. 6.

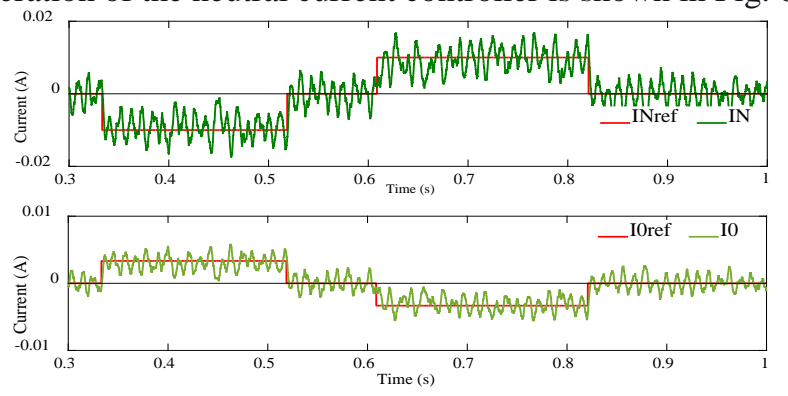

Figure 5. Neutral and Zero sequence currents control. 


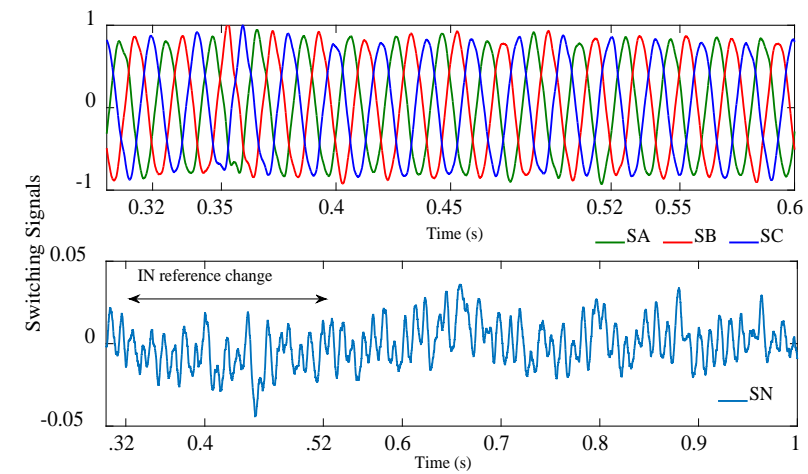

Figure 6. Modulating signals of the four-leg VSI.

From Figs. 5 and 6, it is evident that despite with the system noises, the controller follows the given reference without any significant delay. Further filtering can improve the noisy currents, however, avoided as it does not cause any significant distortion in the main switching signals and output powers as shwon in the next case study.

\section{B. Different faults effects}

Although the designed LV network exhibits inherent voltage unbalance as shown in Fig. 3, intentional severe unbalance cases are applied by introducing asymmetrical faults such as, $2 \mathrm{~L}-\mathrm{G}$ and $1 \mathrm{~L}-\mathrm{G}$ at the PCC. The symmetrical fault, three-phase to ground (3L-G), is also applied to compare the results with the asymmetrical faults from the designed four-leg VSI. The dc-bus voltage shows less rippled regulated output, and similar fault recovery time from the four-leg VSI compared to three-leg VSI during the 3L-G fault from $0.80-1.0 \mathrm{~s}$ as shown in Fig 7. However, during $1 \mathrm{~L}-\mathrm{G}$ and 2L-G faults, the four-leg VSI compensated the dc oscillation more robustly with lower magnitude (around $5 \mathrm{~V}$ ) than the three-leg VSI as highlighted in Fig. 7. The controlled neutral current forces the zero sequence current resulted from the asymmetrical faults to follow actual zero reference resulting improved dc voltage regulation operation from the four-leg VSI. From Fig. 7, it can be concluded that the designed four-leg VSI provides better performance than that of three-leg VSI in terms of power quality.

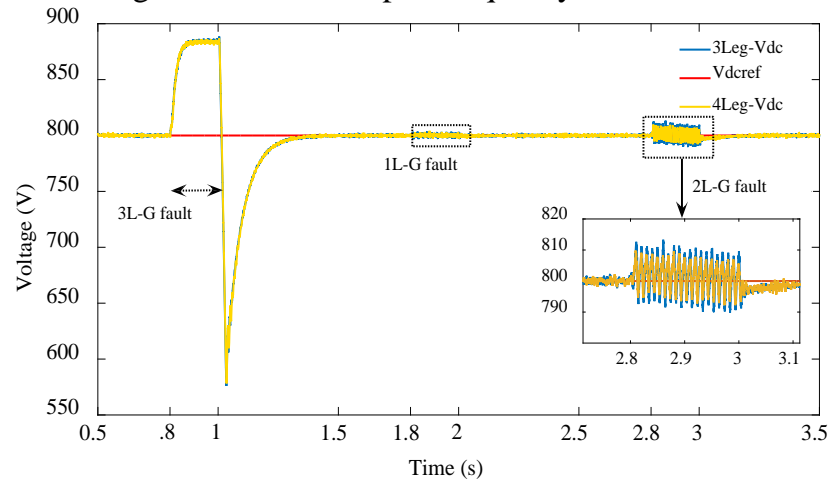

Figure 7. Dc voltage regulation during faults.

Similar performance improvement can be observed from the reactive power compnestaion phenomenon during faults. As the unity p.f operation is utilized for both VSIs, the required reactive power compensation is supplied by the grid to stablize the unbalance system. For 3L-G fault from 0.80 $1.0 \mathrm{~s}$, the four-leg VSI requires around $90 \mathrm{kVar}$, and for 2L$\mathrm{G}$ fault from 2.80-3.0 s, it requires around $50 \mathrm{kVar}$ less compensation support from the grid comapred to the three-leg VSI as shown in Fig. 8. Although, the fault recovery time of the four-leg VSI shows very little improvement (around 5 $\mathrm{ms}$ ) comapred to three-leg VSI, in high power applications with sensitive appliences, even this small improvement can have robust impact on overall system stability restoration.
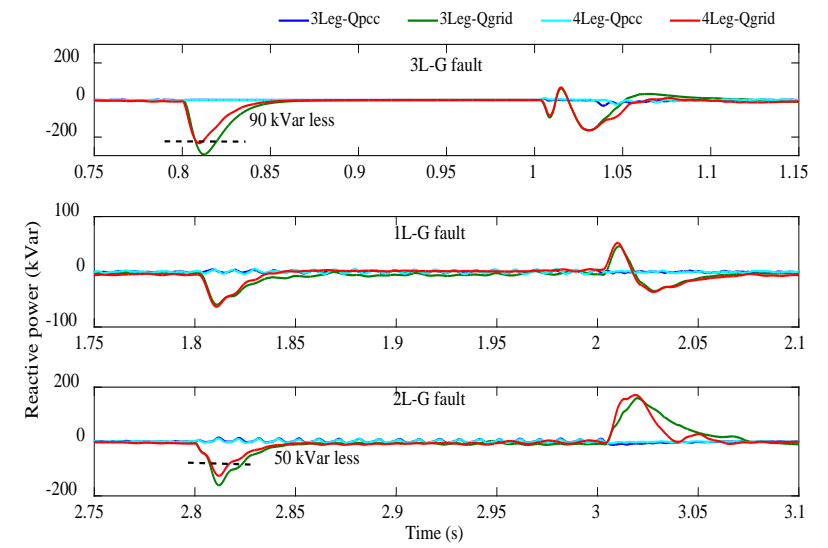

Figure 8. Reactive power compensation during faults.

The active power profiles show similar characteristics for both of the VSIs during the symmetrical fault. However, the four-leg VSI reduces the magnitude of the PV and grid output powers oscillations during assymetrical faults compared to the three-leg VSI as shown in Fig. 9.
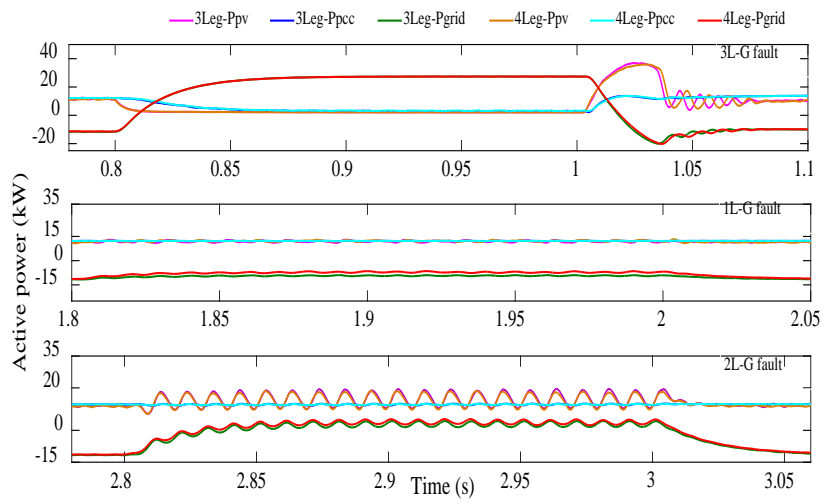

Figure 9. Active power profiles during faults.

The significant improvemet can be observed in the magnitude reduction of the zero sequence voltage during assymetrical faults, i.e. $1 \mathrm{~L}-\mathrm{G}(1.8$ - $2.0 \mathrm{~s})$ and $2 \mathrm{~L}-\mathrm{G}(2.80-$ $3.0 \mathrm{~s}$ ) as shown in Fig. 10. These faults cause unsymmetry in the network resulting severe voltage unbalance scenarios. With the three-leg VSI, the zero sequence voltage results around $200 \mathrm{~V}$ (peak to peak-(pp)) oscillation casuing higher fault current, and sometimes unnecessary triping of the connected devices. With the same system, the four-leg VSI reduces the zero sequence voltage oscillation around $50 \mathrm{~V}$ (pp), and in turn results less fault current. Using four-qudrant operation along with zero sequence current control, the designed model can be operated at complete fault ridethrough (FRT) characteristics. As, in this paper unity p.f 
operation is considered, the designed system does not follow complete FRT feature.

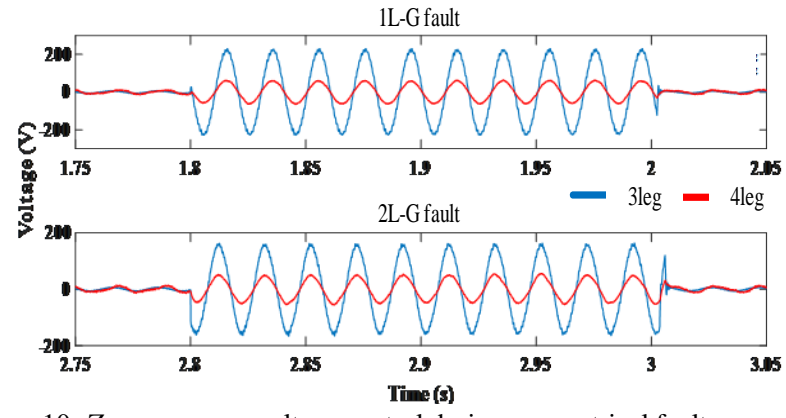

Figure 10. Zero sequence voltage control during assymetrical faults.

\section{CONCLUSION}

The designed four-leg VSI outstands the traditional threeleg VSI in case of network unbalance operating conditions. If balance network is considered, the four-leg VSI would incur additional costs as well as control complexity. However, in practical consideration with three-phase four-wire $\mathrm{LV}$ networks, the unbalanced characteristics are more prevailing than balanced ones. As a result, the designed four-leg VSI would be able to perform more distinctively in real life cases compared to the three-leg VSI. The results also show less compensation MVA requirement with faster fault recovery and less oscillated outputs from the designed four-leg VSI with the control over zero sequence current. Proper synchronous angle detection during network unbalance would be focused in future studies to reduce the double frequency oscillations resulted from the presence of negative sequence components in the unbalanced LV networks.

\section{ACKNOWLEDGEMENT}

The authors of this paper forward their sincerest thanks to ENERGEX, the electric power distribution company owned by the Queensland government, Australia, for providing the distribution network model for this research study.

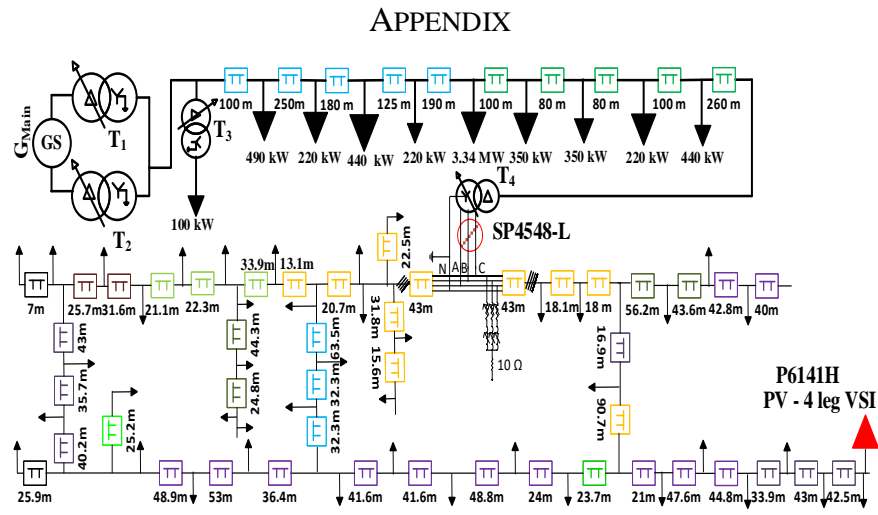

Figure 11. LV network diagram with loads and PV connection.

System description: PV module : 10 series and 2 paraller modules with 108 cells in series and 4 cells in parallel; DC link capacitor $=3000 \mu \mathrm{F}$, switching frequency $=3 \mathrm{kHz}$, simulation time step $=5 \mathrm{~ms}$, Inverter capacity $15 \mathrm{kVA}$; DC voltgae regulator : $\mathrm{Kp}=8, \mathrm{Ti}=0.008$; Current controller $: \mathrm{Kp}=8, \mathrm{Ti}=$ 0.003; neutral and zero sequence current controller: $\mathrm{Kp}=4, \mathrm{Ti}=0.05$; $\mathrm{LCL}$ filter : inverter side $\mathrm{L}=4 \mathrm{mH}, \mathrm{C}=10 \mu \mathrm{F}$, grid side $\mathrm{L}=1 \mathrm{mH}$, damping resistor $=3 \mathrm{~m} \Omega$; Distibution grid: 240 (L-N) /420 (L-L) rms, $50 \mathrm{~Hz}$.

\section{REFERENCES}

[1] L. Yunwei, D. M. Vilathgamuwa and L. P. Chiang, "Microgrid power quality enhancement using a three-phase four-wire grid-interfacing compensator," IEEE Trans. Power Electron., vol. 19, no. 1, pp. 17071719, Nov./Dec. 2005.

[2] P. Lohia, M. K. Mishra, K. Karthikeyan, and K. Vasudevan, "A minimally switched control algorithm for three-phase four-leg VSI topology to compensate unbalanced and nonlinear load,” IEEE Trans. Power Electron., vol. 23, no. 4, pp. 1935-1944, Jul. 2008.

[3] M. J. E. Alam, K. M. Muttaqi, and D. Sutanto, "A three-phase power flow approach for integrated 3-wire MV and 4-wire multi-grounded LV networks with rooftop solar PV," IEEE Trans. on Power Systems, vol. 28, no. 2, pp. 1728-1737, 2012.

[4] Power \& Systems Innovations Inc., Power quality-the basics. [Online]. Available: http://www.psihq.com/iread/pqbasics.htm

[5] S. El-Barbari, and W. Hofmann, "Digital control of four-leg inverter for standalone photovoltaic systems with unbalanced load," in Proc. 26th Annu. Conf. IEEE Ind. Electron. Soc., Oct., 2000, pp. 729- 734.

[6] X. Wang, F. Zhuo, J. Li, L. Wang, and S. Ni, "Modeling and control of dual-stage high-power multifunctional PV system in dqo-coordinate," IEEE Trans. Ind. Electron, vol. 60, no. 4, pp. 1556-1570, 2013.

[7] I. Vechiu, O. Curea, and H. Camblong, "Transient operation of a fourleg inverter for autonomous applications with unbalanced load,” IEEE Trans. Power Electron. vol. 25, pp. 399-407, 2010.

[8] J. C. Wu, H. L. Jou, K. D. Wu, and S. T. Xiao, "Single-phase inverterbased neutral-current suppressor for attenuating neutral current of three-phase four-wire distribution power system," IET Gener. Transm. Distrib. vol. 6, no. 6, pp. 577-583, 2012.

[9] M. J. Hossain, M. A. Mahmud, H. R. Pota, and N. Mithulananthan, "Design of non-interacting controllers for PV systems in distribution networks,” IEEE Trans. on Power Systems, vol. 29, no. 6. pp. 27632774, April, 2014.

[10] C. Schauder, and H. Mehta, "Vector analysis and control of advanced static VAr compensators", IEE Proceedings-C: Generation, Transmission and Distribution, 1993, pp. 299-306.

[11] Charles L. Fortescue, "Method of symmetrical co-ordinates applied to the solution of poly-phase networks". Presented at the 34th annual convention of the AIEE (American Institute of Electrical Engineers) in Atlantic City, N.J. on 28 July 1918.

[12] H.S. Song, K. Nam, "Dual current control scheme for PWM converter under unbalanced input voltage conditions," IEEE Tran. on Industrial Electronics, vol. 46, no. 5, pp.953-959, 1999.

[13] S. Babaei, and S. Bhattacharya, "A control structure for PWM controlled static synchronous compensators under unbalanced conditions and grid faults," International Journal on Electrical Power and Energy System, vol. 71, pp. 160-173, 2015.

[14] F. H. M. Rafi, M.J. Hossain, D. Leskarac, J.Lu, "Reactive power management of a AC/DC microgrid system using a smart PV inverter," IEEE Power and Energy General Meeting, USA, 2015, pp. 1-5.

[15] A. Yazdani and R. Iravani, "A unified dynamic model and control for the voltage-sourced converter under unbalanced grid conditions," IEEE Trans. on Power Deliv. vol. 21, pp. 1620-29, 2006.

[16] F.H.M. Rafi, M.J. Hossain, and J. Lu, "Design of a single stage transformerless VSI in a smart microgrid for PV-STATCOM/ESS operations," Australasian Universities Power Engineering Conference (AUPEC), Perth, 2014, pp. 1-6.

[17] C. Bajracharya, M. Molinas, J. A. Suul, and T. M. Undeland, "Understanding of tuning techniques of converter controllers for VSCHVDC”. Available online: http://lib.tkk.fi/Conf/2008/urn011658.pdf.

[18] M. N. Kabir, Y. Mishra, G. Ledwich, Z. Y. Dong, and K. P. Wong, "Coordinated control of grid-connected photovoltaic reactive power and battery energy storage systems to improve the voltage profile of a residential distribution feeder," IEEE Transactions on Industrial Informatics, vol. 10, no. 2. pp. 967-977, 2014. 